HNX: Nhìn lại 02 năm nhiệm kỳ Hội đồng chỉ số đầu tiên của Sở GDCK Hà Nội

Ủy ban Chứng khoán Nhà nước

Ngày 8 tháng 5 năm 2014

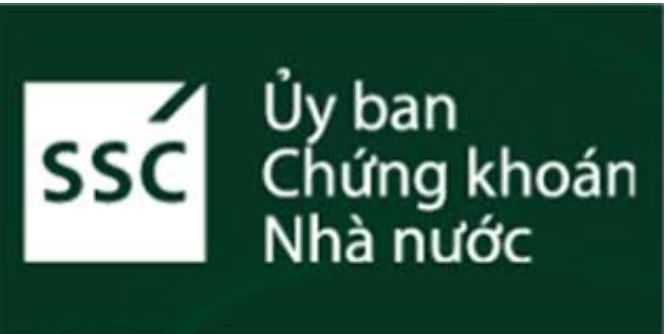

http://www.ssc.gov.vn/ubck/faces/oracle/webcenter/portalapp/pages/vi/noidungtin.jspx?dDo cName=APPSSCGOVVN162088854\&_adf.ctrl-

state $=1533$ tblekp_17\&_afrLoop $=68625095224000 \&$ afrWindowMode $=0 \&$ afrWindowld $=1533$ tblekp_14 


\section{HNX: Nhìn lại 02 năm nhiệm kỳ Hội đồng chỉ số đầu tiên của Sở GDCK Hà Nội Đăng ngày: 08/05/2014}

Ngày 7/5/2014, Sở GDCK Hà Nội tổ chức phiên họp thứ 06 của Hội đồng chỉ số HNX. Đây cũng là phiên họp khép lại 02 năm nhiệm kỳ đầu tiên của Hội đồng chỉ số thành lập theo Quyết định số 143/QĐ-SGDHN ngày 18/5/2012 của Sở GDCK Hà Nội (HNX). Tại phiên họp, Hội đồng chỉ số đã tổng kết quá trình vận hành các bộ chỉ số HNX giai đoạn 2/12/2013 - 31/3/2014; xem xét định kỳ các bộ chỉ số và nguyên tắc xây dựng một số chỉ số mới đồng thời công bố thay đổi thành viên Hội đồng.

Với chức năng tham mưu, tư vấn và đưa ra ý kiến độc lập mang tính quyết định đối với các vấn đề về việc duy trì và vận hành các chỉ số tại Sở GDCK Hà Nội, trong suốt 02 năm qua, Hội đồng chỉ số đã hoạt động rất tích cực và hiệu quả. Với Bộ Nguyên tắc Xây dựng và Quản lý Chỉ số HNX 30 (chỉ số HNX 30), Hội đồng chỉ số đã đạt được bước tiến đầu tiên trong việc xây dựng và cung cấp cho TTCK Việt Nam những công cụ chỉ báo và đầu tư mới. Tiếp nối thành công của chỉ số HNX 30, Hội đồng chỉ số đã phát triển Bộ Nguyên tắc xây dựng và quản lý chỉ số giá cổ phiếu để làm cơ sở vận hành các bộ chỉ số chỉ báo của HNX và cho ra mắt HNX FF Index, Bộ chỉ số Quy mô và Bộ chỉ số Ngành. Trong giai đoạn từ $02 / 12 / 2013-31 / 3 / 2014$, các chỉ số của $\mathrm{HNX}$ đều có mức tăng tương ứng từ $31 \%-50 \%$. Trong đó, chỉ số HNX 30 là chỉ số có mức tăng cao nhất trong số 7 chỉ số của Sở GDCK Hà Nội trong cùng kỳ xem xét với mức tăng hơn $50 \%$.

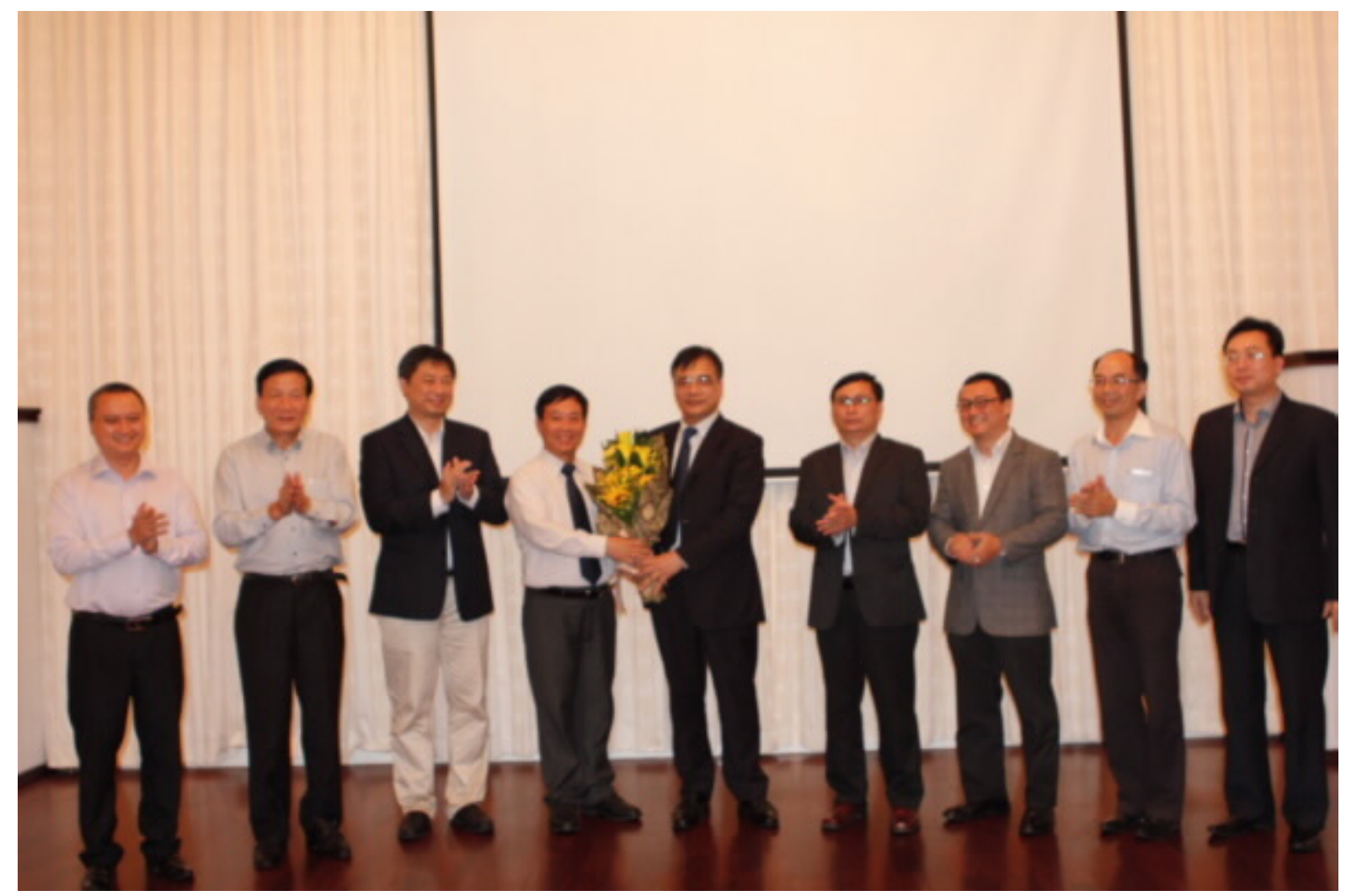

Các thành viên Hội đồng chỉ số Ảnh: TT

Tại phiên họp, Hội đồng chỉ số đã xem xét sơ bộ và định hướng hoàn thiện chỉ số thu nhập (Total Return Index), chỉ số được xem như công cụ giúp các quỹ đầu tư đo lường hiệu quả các danh mục đầu tư của mình. Bộ nguyên tắc vận hành chỉ số này dự kiến sẽ ban hành vào tháng 10 năm nay để chuẩn bị cho sự ra đời của thị trường ETF trong năm 2014. Bên cạnh đó, Hội đồng chỉ số cũng chốt phương án vận hành của chỉ số trái phiếu thực (Actual Bond), dự kiến ra mắt trong vòng 1 đến 2 tháng tới và đặt 
nền móng nghiên cứu cơ bản đối với một chỉ số đánh giá mức độ minh bạch và công bố thông tin đối với các công ty niêm yết.

Phiên họp lần này đã chia tay với 03 thành viên Hội đồng gồm: GS.TS. Nguyễn Văn Nam (Trường ĐH Kinh tế Quốc dân), TSKH. Nguyễn Thành Long (Phó Chủ tịch UBCKNN), ThS. Cung Trần Việt (Thành viên Hội đồng Quản trị $\mathrm{VCF}$ ) và chào đón 03 thành viên mới gồm PGS.TS.Trần Đình Thiên (Viện trưởng Viện Kinh tế Việt Nam), TS. Nguyễn Sơn (Vụ trưởng Vụ Phát triển thị trườngUBCKNN), Th.S Trịnh Hoài Giang (Phó TGĐ HSC). Các thành viên Hội đồng vẫn tiếp tục song hành cùng Hội đồng gồm TS. Bùi Trường Giang (Vụ trưởng Phụ trách Vụ Tổng hợp, Văn phòng Chủ tịch nước), TS. Nguyễn Anh Tuấn (Tổng biên tập báo Đầu tư), TS. Vương Quân Hoàng (Đại học Tổng hợp Brussels), ThS. Phạm Ngọc Bích (Tổng Giám đốc VietNam Holding Asset Management), ThS. Trần Lê Minh (Phó TGĐ VFM) và ThS. Nguyễn Anh Phong (Phó TGĐ Sở GDCK Hà Nội).

Phát biểu tại cuộc họp, Chủ tịch HĐQT kiêm Tổng Giám đốc HNX Trần Văn Dũng đánh giá cao nỗ lực và kết quả hoạt động của Hội đồng nhiệm kỳ đầu tiên. Nhiệm kỳ này đã để lại những dấu ấn sâu sắc và nền móng ban đầu để tiếp tục phát triển hệ thống chỉ số của Sở GDCK Hà Nội. Những định hướng phát triển mang tính cơ bản của Hội đồng chỉ số nhiệm kỳ I là tiền đề để tiếp tục phát triển những sản phẩm mới, giúp thị trường chứng khoán Việt Nam trở nên bền vững và hấp dẫn hơn. 